University of Texas Rio Grande Valley

ScholarWorks @ UTRGV

$12-2011$

\title{
Fabrication of Mineralized Collagen from Bovine Waste Materials by Hydrothermal Method as Promised Biomaterials
}

\author{
Faheem A. Sheikh \\ The University of Texas Rio Grande Valley \\ M. A. Kanjwal \\ Javier Macossay-Torres \\ The University of Texas Rio Grande Valley, javier.macossaytorres@utrgv.edu \\ Muneeb A. Muhammad \\ Travis Cantu \\ The University of Texas Rio Grande Valley
}

See next page for additional authors

Follow this and additional works at: https://scholarworks.utrgv.edu/chem_fac

Part of the Animal Sciences Commons, and the Chemistry Commons

\section{Recommended Citation}

Sheikh, F. A., Kanjwal, M. A., Macossay, J., Muhammad, M. A., Cantu, T., Chronakis, I. S., Barakat, N. A. M., \& Kim, H. Y. (2011). Fabrication of Mineralized Collagen from Bovine Waste Materials by Hydrothermal Method as Promised Biomaterials. Journal of Biomaterials and Tissue Engineering, 1(2), 194-197. https://doi.org/10.1166/jbt.2011.1017

This Article is brought to you for free and open access by the College of Sciences at ScholarWorks @ UTRGV. It has been accepted for inclusion in Chemistry Faculty Publications and Presentations by an authorized administrator of ScholarWorks@ UTRGV. For more information, please contact justin.white@utrgv.edu,william.flores01@utrgv.edu. 


\section{Authors}

Faheem A. Sheikh, M. A. Kanjwal, Javier Macossay-Torres, Muneeb A. Muhammad, Travis Cantu, loannis S. Chronakis, N. A. M. Barakat, and Hak Yong Kim 


\title{
Fabrication of Mineralized Collagen from Bovine Waste Materials by Hydrothermal Method as Promised Biomaterials
}

\author{
Faheem A. Sheikh ${ }^{1}$, Muzafar A. Kanjwal ${ }^{2}$, Javier Macossay ${ }^{1}$, Muneeb A. Muhammad $^{3}$, \\ Travis Cantu ${ }^{1}$, Nasser A. M. Barakat ${ }^{4}$, and Hak Yong Kim ${ }^{4}$ \\ ${ }^{1}$ Department of Chemistry, University of Texas Pan American, Edinburg, TX, 78539, USA \\ ${ }^{2}$ Technical University of Demmak, DTU Food, Soltofts Plads, B 227. 2800. Kgs. Lyngby Denmark \\ ${ }^{3}$ Department of Chemical Engineering and Chemistry, Technische Universiteit, Eindhoven, 513, \\ The Netherlands ${ }^{4}$ Department of Organic Materials and Fiber Engineering, Chonbuk National \\ University, Jeonju, 561-756, South Korea
}

\begin{abstract}
In the present study, we aimed to produce mineralized-collagen by hydrothermal process. A simple method not depending on additional foreign chemicals has been employed to isolate the mineralized-collagen fibers from bovine waste. The process of extraction involves the use of hydrothermal method from available bovine bones. The structural and morphological properties of the collagen fibers were characterized by using scanning electron microscopy and transmission electron microscopy. These results indicated well received collagen fibers, having a diameter less than $1 \mu \mathrm{m}$ and with established mineral content in the individual fibers. The X-ray diffraction showed the crystalline feature of the obtained nano-compounds. The thermo gravimetric analysis was used to differentiate between the collagen and mineral parts of obtained product. Overall, the results generously indicated production of well received collagen fibers from bovine bones.
\end{abstract}

\section{Keywords}

Collagen; Hydroxyapatite; Crystalline; Fibers and Bone

\section{INTRODUCTION}

\begin{abstract}
In recent years, tremendous efforts had been put forward to produce biomaterials for bone tissue engineering applications. The bone tissue composition is a well-known which accounts to made from mineral/organic hybrids of hydroxyapatite (HAp) $\left(\mathrm{Ca}_{10}\left(\mathrm{PO}_{4}\right)_{6}(\mathrm{OH})_{2}\right)$ and organic (mainly collagen). HAp is of special interest, because it can mimic the composition of natural bone and has a close structural and chemical resemblance with natural bone. ${ }^{1-2}$ Therefore, HAp has been widely used for a variety of bone filling and augmentation applications. On the other hand, a synergistic effect is displayed by collagen, which leads to accelerated bone healing. ${ }^{3-4}$ The strategies to acquire combined properties of these important materials to fabricate HAp-collagen composites are most widely used to impart osteointegration. ${ }^{5}$ Similarly, other efforts have been made to produce bone-like apatite and apatite/collagen composites to solve this needful purpose ${ }^{6-9}$ Due to the advancements in nanotechnology, these novel hybrids consisting of collagen and HAp with structural feature resembling natural bone are considered as a promising biomaterial for the
\end{abstract}

Copyright (C) 2011 American Scientific Publishers All rights reserved

Correspondence to: Faheem A. Sheikh. 
induction of new bone formation. ${ }^{3-5}$ In this regard, the mineralized-collagen which posses both aforementioned characters has become an ideal material, as it imparts the dual purpose, required for host tissue regeneration. ${ }^{5}$

In this communication, we introduce a novel way to step forward towards the production of mineralized-collagen which will be used as future biomaterial. Many research dates show different methods for the production of these important materials, and had been achieved by various routes like electric field orientation, high magnetic field, enzymatic mineralization, induction by simulated body flu-ids, and by growing in presence of human mesenchymal stem cells to induce mineralization. ${ }^{10-14}$ However, to the best of our knowledge there is no such report to deal with the production of mineralized-collagen from bovine bones by simple hydrothermal method.

\section{EXPERIMENTAL PROCEDURE}

A cylindrical hydrothermal stainless steel autoclave with internal diameter of $6 \mathrm{~cm}$, external of $7.4 \mathrm{~cm}$ and a height of $15 \mathrm{~cm}$ was used in this process. Bovine bones taken from fumer of Egyptian cows were carefully washed by water and acetone to remove the fats and other solid impurities associated with them. After careful washing, the bones have been dried at $160{ }^{\circ} \mathrm{C}$ for $48 \mathrm{~h}$. The cleaned bones were grinded to a particle size of less than $200 \mu \mathrm{m}$. The ground bones were placed in an open Teflon crucible and were added to de-ionized water at solid to liquid weight ratio of 1:40. Then the crucible was placed inside the stainless steel autoclave (inset figure of Scheme 1). Nitrogen gas has been used to remove the dissolved oxygen from the water and the atmosphere surrounding the crucible. The autoclave was tightly sealed and heated in silicon oil bath at $300{ }^{\circ} \mathrm{C}$ for $1 \mathrm{~h}$. The autoclave was cooled by quenching in big amount of cold water. The obtained product was filtered and subsequently dried.

\section{CHARACTERIZATION}

The morphology of the mineralized-collagen was analyzed with a field emission scanning electron microscope (FE-SEM, Hitachi S-7400, Japan). The samples for FE-SEM were prepared by mounting the previously dried samples onto aluminum stubs, and sputter coated with osmium for 30 seconds Transmission electron microscopy (TEM) was performed with JEOL 2010 operating at $200 \mathrm{kV}$ (JEOL Ltd., Japan). The samples for TEM measurements were prepared by dipping the copper grid in $(1 \mathrm{mg} / \mathrm{ml})$ an aqueous dispersion of sample. For staining a drop of $2 \%$ phosphotungstic acid (PTA) solution was pipetted out by micropipette on freshly dipped TEM copper grid. The extra solution was removed by using a Kimwipes and the grid was allowed to dry overnight under vacuum. Before loading, the samples were sonicated in an ultra-sonicator bath for $1 \mathrm{~min}$. The information about the phases and crystallinity was obtained using Rigaku X-ray diffractometer (Rigaku Co., Japan) with $\mathrm{Cu}$ $\mathrm{K} a(\lambda=1.54056 \AA)$ radiation over Bragg angles ranging from 10 to $80^{\circ}$. The thermal stability of the samples was carried out with a Pyris TGA (Perkin Elmer Co., USA) by heating samples from 37 to $800{ }^{\circ} \mathrm{C}$ under a continuous oxygen purge of $10 \mathrm{~mL} / \mathrm{min}$. The heating rate was $20^{\circ} \mathrm{C} / \mathrm{min}$.

\section{RESULTS AND DISCUSSION}

Bone is known to be mainly composed of HAp minerals and collagen fibers. The extracts prepared in this study were structurally similar to that of existing natural system. At the first stage of characterization of the products, the physicochemical appearance of samples was achieved by careful analyses of FE-SEM and TEM. In this regard, the Figure 1(A) shows morphology of the obtained mineralized-collagen after drying. As pictured, we can see well distribution of collagen bundles in its unique natural pattern. In more details, the collagen 
bundles are well dispersed and are arranged linearly with a diameter ranging less than $1 \mu \mathrm{m}$. It is noteworthy to mention, that the natural collagen exists as weaving patterns which is predominantly obvious from the obtained FE-SEM results. In addition to this, it can also be observed small particles are present over the surfaces of fibers; we believe these structures are mineralized portion of a biomaterial (i.e., HAp). However, due to poor resolution of FESEM, we could not clearly see these predicted structures. Therefore, to clear this dilemma the TEM analyses had been invoked. Furthermore, to get more insights about the crystalline feature of the fibers, the results from TEM analyses are presented in Figure 1(B). In this figure, it can clearly be seen that fibrous nature of the collagen is present resembling with the FE-SEM results. These results further on confirm the FE-SEM results. Moreover, it can be also observed that small particles like structures are associated with the individual fibers. As mentioned earlier, the mineralized particles could not be seen while analyzing through FE-SEM. We believe these particles are apatite nuclei which further confirm the existence of obtained mineralized-collagen.

It is well known that XRD analysis can be utilized to differentiate between two different crystalline species with regard to variant crystal patterns. In order to find out the crystalline characteristics of mineralized parts of the collagen, the samples where characterized by using XRD analyses. In this concern, Figure 2 shows the XRD pattern of the obtained mineralized-collagen. From this figure, we can see the vertical base lines represent the standard HAp according to the standard JCPDS data base. ${ }^{15-16}$ As shown in this figure, all the peaks corresponding to the standard HAp originating from the base lines are matching with the spectra of the HAp commercially purchased HAp. On the other hand, spectrum of the mineralized-collagen is also represented in this figure; the diffraction pattern meets almost with the diffraction pattern of standard Hap, which assures the presence of mineral calcium and phosphorous. In the scenario, it can be observed that diffraction peaks of the mineralized-collagen fibrils are indeed situated between the exact positions, which are expected for HAp. Especially, a major peak at $15.49^{\circ}$ corresponding to a d spacing of 6.77 $\AA$, is too strong compared with the other diffraction peaks. This peak perfectly, matches with the octacalcium phosphate. In more details, the spectra posses the peaks at $2 \theta$ values of $25.35,28.96,31.77,32.19,32.90,34.04,39.81,46.71,49.46$ and $54.44^{\circ}$ corresponding to the crystal planes (210), (211), (112), (300), (202), (310), (222), (213) and (104), respectively, indicate the presence of well mineralized part inside the collagen fibers. ${ }^{16}$

The thermo gravimetric analyses for weight losses and derivative of weight losses of obtained mineralized-collagen slurry and commercially purchased HAp are shown in Figures 3(A) and (B). In the Figure 3(A), it can be seen that mineralized-collagen had started degrading from $216^{\circ} \mathrm{C}$ and had been completely burned out at $346^{\circ} \mathrm{C}$ temperature. With further increase with temperatures, the $20 \%$ residual weight is still remaining, this high residual weight remaining accounts for the mineralized part of collagen. Therefore, the mineralized part of collagen remains as un-burnt with increase in temperature up to $800{ }^{\circ} \mathrm{C}$. However, in case of the HAp, (Fig. 3(B)) which consists of HAp as major portion; we can see the sharp degradation starts from $65^{\circ} \mathrm{C}$ and ends up to $250{ }^{\circ} \mathrm{C}$ this temperature range is accounted for collagen and other impurities associated with preparation method. Meanwhile, it can be clearly seen that after $250{ }^{\circ} \mathrm{C}$ onwards there is no decrease in the further weight loss. This continuous same weight remaining up to $70 \%$ is accounting for the HAp which is densely present in this filtrate. Furthermore, the degradation pattern confidently encourages the degree and style which was followed by our mineralized-collagen samples.

The whole procedure for making the ideal mineralized-collagen was described carefully. We introduce a generalized scheme to summarize the procedure and to justify production of mineralized-collagen fibers bearing HAp NPs; therefore, they will be used as suitable candidates for biomedical applications. Briefly, (Scheme 1) indicates that the mineralized- 
collagens were obtained from hydrothermal process of bovine bones. Initially, bones were washed with water and acetone to remove the solid impurities associated from them. After washing, the bones were physically grounded into pieces and with a ball milling to obtain particulate size. Further after this step, samples were placed in an autoclave and further subjected to high temperature and pressure by using high temperature bath for an hour as a retention time. Furthermore, after the specified incubation samples were removed out and filtrated to separate the mineralized-collagen and HAp.

\section{CONCLUSION}

In conclusion, an economical way to isolate the well received mineralized-collagen can be obtained by simple hydrothermal method. The FE-SEM and TEM analyses can be helpful to describe the morphology of individual mineralized-collagen fibers at nanoscale level. The XRD technique can be helpful to find out the crystalline nature of mineralized-collagen. Furthermore, the TGA technique can be used to distinguish between the collagen and non collagen parts. Hence, a multi-component material consisting of collagen and HAp developed here may be a promising candidate for bone tissue engineering.

\section{Acknowledgments}

The author is thankful for support by grant from the Korean Ministry of Education, Science and Technology (The Regional Core Research Program/Center for Healthcare Technology and Development, Chonbuk National University, Jeonju 561-756 Republic of Korea). Faheem A. Sheikh and Javier Macossay are thankful for partial financial support for this work from NIH-NIGMS-NIA grant \# 1SC2AG036825-01.

\section{References and Notes}

1. Rovira A, Bareille R, Lopez I, Rouais F, Bordenave L, Rey C, Rabaud M. J Mater Sci Mater Med. 1993; 4:372.

2. Mathers NJ, Czernuszka JT. J Mater Sci Lett. 1991; 10:192.

3. Huang Z, Tian J, Yu B, Xu Y, Feng Q. Biomed Mater. 2009; 4:7.

4. Yang H, Zhang Q. J Mater Sci Technol. 2001; 17:495.

5. Kathagen BD, Mittelmeier H. Arch Orthop Trauma Surg. 1984; 103:291. [PubMed: 6529345]

6. Stupp SI, Ciegler GW. J Biomed Mater Res. 1992; 26:169. [PubMed: 1569112]

7. Stupp SI, Mejicano GC, Hanson JA. J Biomed Mater Res. 1993; 27:289. [PubMed: 8360199]

8. Doi Y, Horiguchi T, Moriwaki Y, Kitago H, Kamimoto T, Iwayama Y. J Biomed Mater Res. 1996; 31:43. [PubMed: 8731148]

9. Wang RZ, Cui FZ, Lu HB, Wen HB, Ma CL, Li HD. J Mater Sci Lett. 1995; 14:490.

10. Ficai A, Andronescu E, Trandafir V, Ghitulica C, Voicu G. Mater Lett. 2010; 64:541.

11. Wu C, Sassa K, Iwai K, Asai S. Mater Lett. 2007; 61:1567.

12. Yamauchi K, Goda T, Takeuchi N, Einaga H, Tanabe T. Bio-materials. 2004; 25:5481.

13. Zhang LJ, Feng XS, Liu HG, Qian DJ, Zhang L, Yub XL, Cui FZ. Mater Lett. 2004; 58:719.

14. Niemeyer P, Krause U, Fellenberg J, Kasten P, Seckinger A, Ho AD, Simank HG. Cells Tissues Organs. 2004; 177:68. [PubMed: 15297781]

15. JCPDS Card No. 1994; 9:432.

16. Sheikh FA, Barakat NAM, Kanjwal MA, Park DK, Park SJ, Kim HY. Macromol Res. 2010; 18:59.

17. Wahl DA, Sachlos E, Liu CZ, Czernuszka JT. J Mater Sci Mater Med. 2007; 18:201. [PubMed: 17323151] 


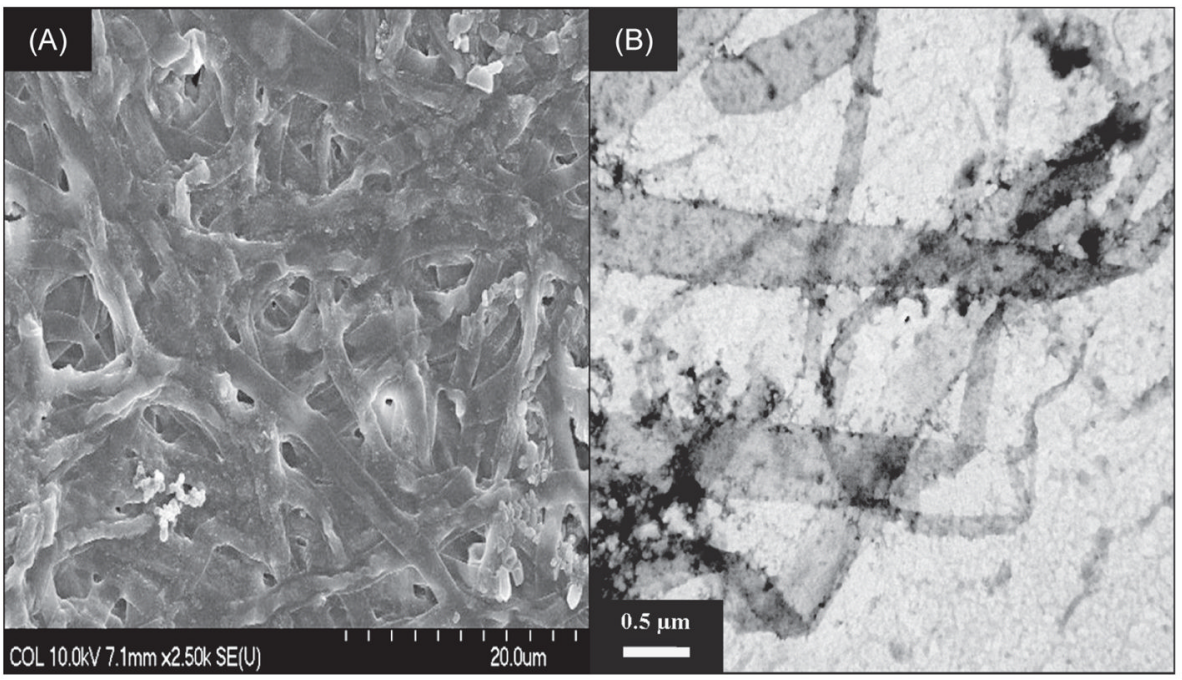

Fig. 1.

Field emission scanning electron microscopy (FE SEM) images for the mineralized-collagen fibers; (A) and Transmission electron microscopy (TEM) of the mineralized-collagen fibers; (B). 


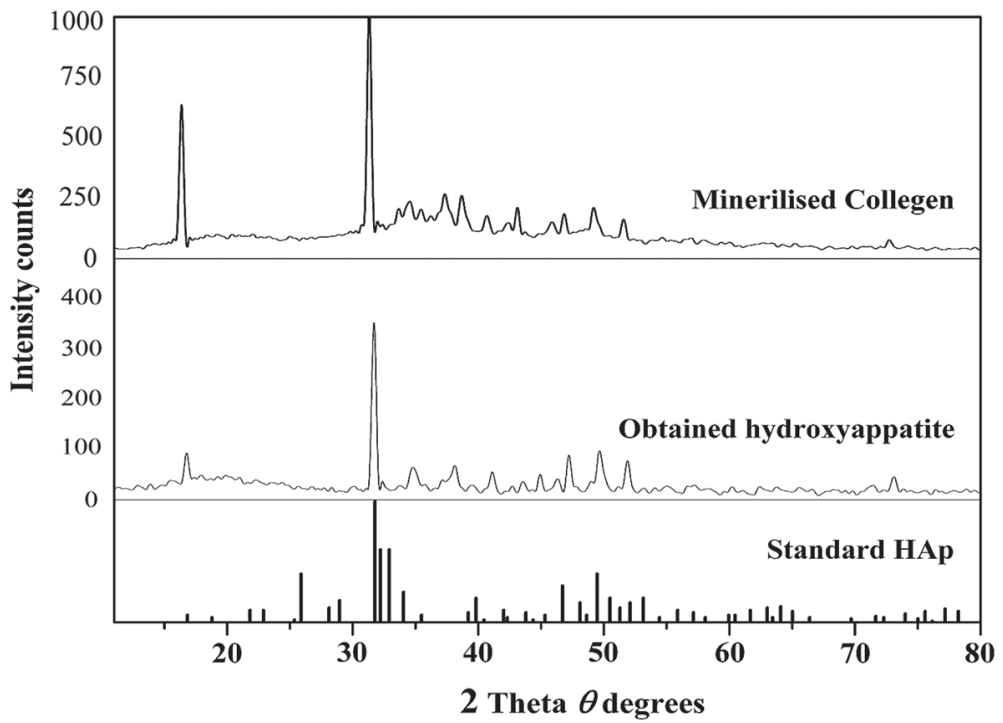

Fig. 2.

XRD results for the standard (the vertical base lines) and prepared hydroxyapatite (calcined). Also, the spectra of mineralized-collagen fibers. 

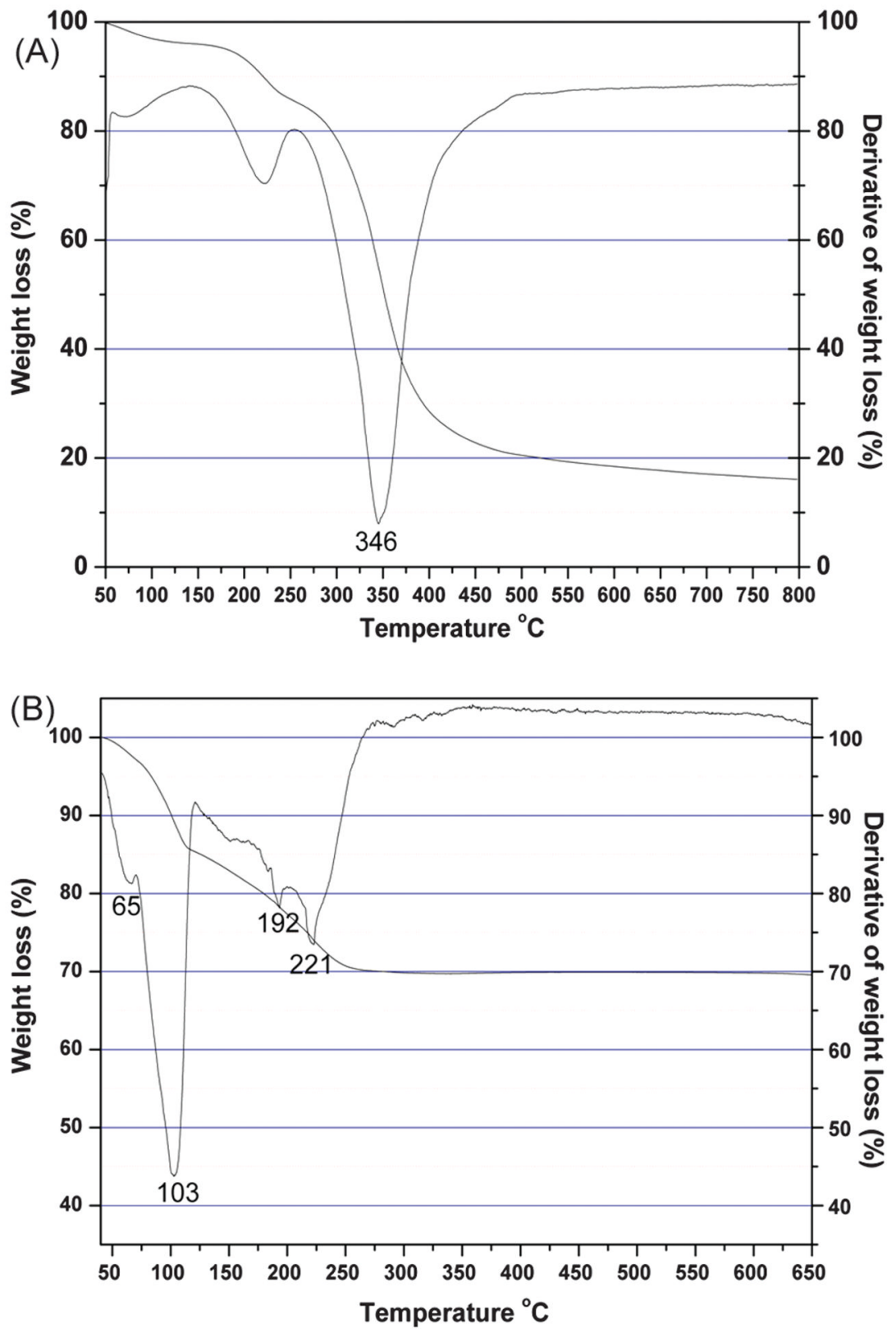

Fig. 3.

Thermal behavior of mineralized-collagen fibers; (A) and thermal weight loss from obtained hydroxyapatite; (B). 


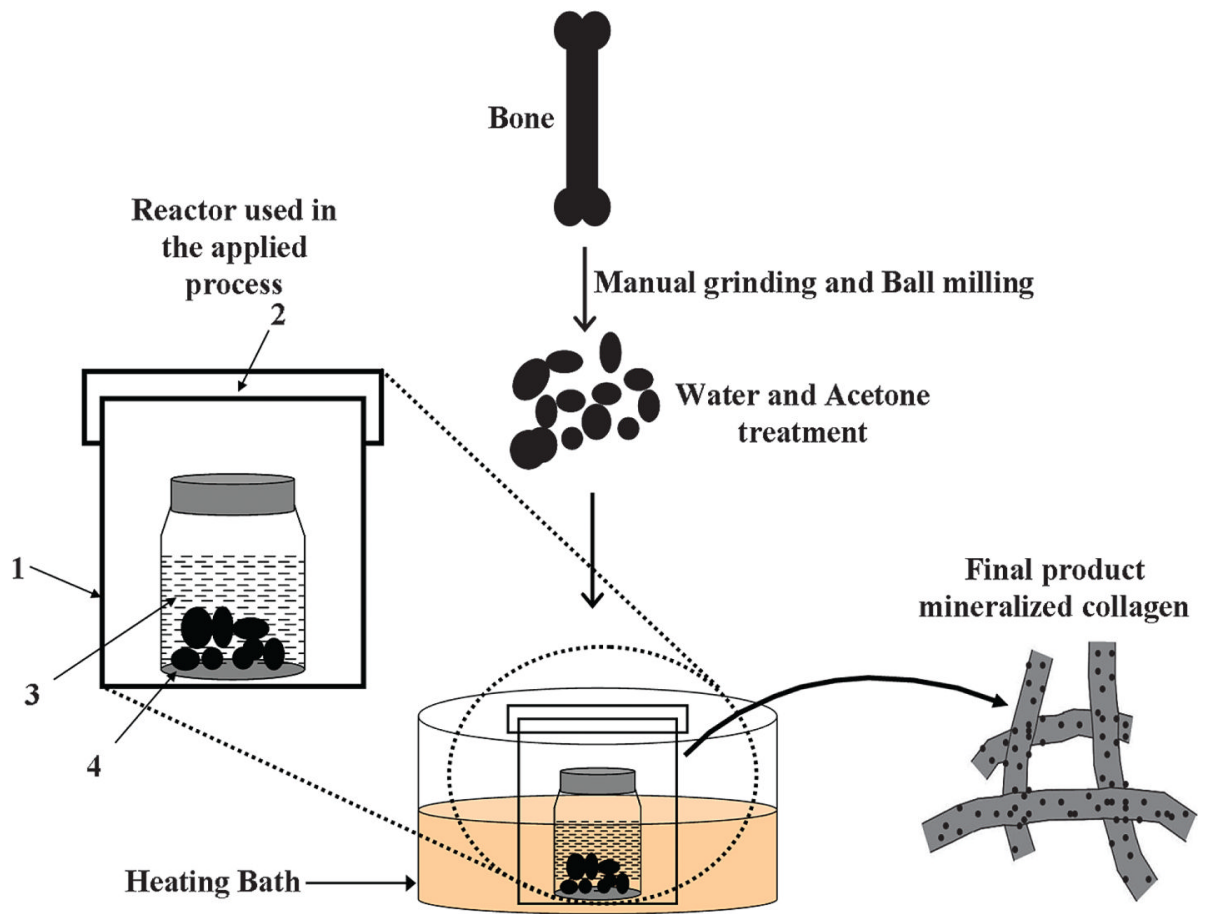

Scheme 1.

The systematic presentation for this novel strategy. Inset figure, shows the high magnification for used bio-reactor: (1) the reactor, (2) top lid, (3) teflon bottle filled with water, (4) the grinded bone particles. 